Goldschmidt 2021 Abstract

https://doi.org/10.7185/gold2021.7139

\section{Initial results of the first visible and near-infrared spectrometer on the Martian surface: SuperCam unveils Jezero crater's ground mineralogy}

LUCIA MANDON ${ }^{1}$, THIERRY FOUCHET ${ }^{1}$, OLIVIER FORNI $^{2}$, JEFFREY R JOHNSON ${ }^{3}$, OLIVIER GASNAULT ${ }^{2}$, PROF. CATHY QUANTIN-NATAF ${ }^{4}$, PIERRE BECK ${ }^{5}$, ANN M OLLILA $^{6}$, CLÉMENT ROYER ${ }^{1}$, FRANCOIS POULET $^{7}$, CÉDRIC PILORGET $^{7}$, PERNELLE BERNARDI ${ }^{1}$, JEANMICHEL REESS ${ }^{1}$, RAYMOND T NEWELL ${ }^{6}$, SYLVESTRE MAURICE $^{2}$ AND ROGER WIENS ${ }^{6}$

${ }^{1}$ LESIA

${ }^{2}$ IRAP

${ }^{3} \mathrm{JHU}$ APL

${ }^{4}$ LGL-TPE, Univ. Lyon

${ }^{5}$ Institut de Planétologie et d'Astrophysique de Grenoble

${ }^{6}$ LANL

${ }^{7}$ IAS

Presenting Author: lucia.mandon@obspm.fr

The Perseverance rover (Mars 2020 mission, NASA) landed in the ancient crater lake Jezero, Mars on February $18^{\text {th }}, 2021$. The main science objectives of the mission are the characterization of past habitable environments, the search for preserved biosignatures and the collection of samples to be returned to Earth by the MSR (Mars Sample Return, NASA/ESA) mission $[1,2]$. The payload includes the SuperCam instrument (under LANL, USA and IRAP, France leadership), which plays a decisive role in the exploration strategy, as it combines various remote-sensing techniques to investigate the elemental and mineralogical composition of rocks and soils: high-resolution color imaging, laser-induced breakdown spectroscopy, Raman spectroscopy, visible and near-infrared (VISIR) reflectance spectroscopy, and acoustic sensing [3, 4, 5]. In particular, the near-infrared spectrometer is a novel instrument on the Martian surface. The produced spectra, together with data from two additional visible spectrometers, cover the $0.39-0.85 \mu \mathrm{m}$ and 1.3-2.6 $\mu \mathrm{m}$ range, which allows for the identification of a wide variety of minerals.

Orbital data shows that the landing site exhibits diverse mineralogical assemblages in various geological contexts, attesting in particular an aqueous activity during the Noachian and Hesperian eras (>3 Ga), and including mafic minerals, carbonates, phyllosilicates and opaline silica $[2,6,7,8]$. We will present the initial results of the SuperCam VISIR spectrometers, with calibrated [9] spectral data collected in the first four months of operation of the instrument. The mineralogical interpretation is expected to bring new insights into the site geology and into the Early Mars environments, as well as refining the sampling strategy of the rocks that will be sent to Earth and analyzed by generations of scientists for decades to come.

\section{References}

[1] Farley, K. A. et al., 2020. Space Sci. Rev; [2] QuantinNataf, C. et al., this conference; [3] Wiens, R.C. et al., 2017.
Spectroscopy; [4] Maurice, S. et al., this conference; [5] Cousin, A. et al., this conference; [6] Goudge, T.A. et al., 2015. J. Geophys. Res. Planets; [7] Ehlmann, B.L. et al., 2008. Science; [8] Tarnas, J.D. et al., 2019. Geophys. Res. Lett.; [9] Royer, C. et al., this conference. 